\title{
Synergistic Cytotoxic Effect of Honey bee venom and Cisplatin on Tongue Squamous Cell Carcinoma
}

Sabreen Gamal Khalil ( $\nabla$ sabrin.gamal@mu.edu.eg )

Faculty of dentistry,Minia university https://orcid.org/0000-0003-1858-1993

Amr Helmy Mustafa El-Bolok

Faculty of dentistry, Minia university

Sherif Farouk El-Gayar

Faculty of dentistry, Minia university

Maii Ibrahim Sholkamy

Faculty of dentistry, Minia university

\section{Research Article}

Keywords: Honey bee venom, Cisplatin, SCC-25 cells, Apoptosis

Posted Date: October 19th, 2021

DOl: https://doi.org/10.21203/rs.3.rs-970940/v1

License: (c) (1) This work is licensed under a Creative Commons Attribution 4.0 International License. Read Full License 


\section{Abstract}

Background: Cancer is a serious issue that has a significant effect on the health of all human communities. Tongue cancer is one of the most common head and neck cancers in the world. In the medical world, cancer therapy is a major challenge. Nowadays, natural compounds are important resources of many anti-cancer medications. Venom from honey bees possesses potent anti-cancer effects. Cisplatin is a chemotherapeutic drug that has been used for decades to treat cancer cells. Recently, Combination therapy has been a popular treatment choice for cancer patients.

This study aimed to investigate the synergistic cytotoxic effect of honey bee venom (BV) and cisplatin on tongue squamous cell carcinoma cell line (SCC-25).

Methods: The cytotoxic effect was determined using Methyl Thiazol Tetrazolium (MTT) assay, microscopic examination, P53 and caspase-3 were quantified by Real-Time Polymerase chain reaction (RT-PCR) and statistical analysis.

Results: The findings revealed that the tested drugs' cytotoxic potential against SCC-25 cells is dose dependent. The half-maximal inhibitory concentration $\left(\mathrm{IC}_{50}\right)$ value of MTT assay of BV/cisplatin mix decreased significantly compared to $\mathrm{IC}_{50}$ values of $\mathrm{BV}$ and cisplatin in sole formulation. Microscopic examination showed that $\mathrm{BV}$ and cisplatin alone and in combination mainly produced apoptotic cell death. Regarding RT-PCR results, P53 and caspase-3 expression were significantly increased in SCC-25treated cells $(P=0.0001)$.

Conclusions: The combined use of BV and cisplatin induced marked synergistic cytotoxic effect on SCC25 cell line.

\section{Background}

Cancer has become one of the globe's leading causes of death and morbidity. In 2020, the World Health Organization (WHO) estimated 19.3 million cases of cancer diagnosed worldwide with 10.0 premature mortality (1).

Tongue squamous cell carcinoma is the most common oral cavity malignancy (2).

Head and neck cancer has been treated with a variety of methods including surgery, radiotherapy and chemotherapy. Chemotherapy remains the most often used treatment. Sometimes, it may have a variety of side effects (3).

As a result, scientists are becoming increasingly popular in natural biological medicines as a source of anti-cancer pharmaceuticals in order to improve therapy efficacy while reducing unwanted side effects (4). 
Apitherapy is a type of alternative medicine in which honey bee products, specifically bee venom (also known as apitoxin), are employed in the treatment of a wide range of human disorders (5).

BV has long been utilized in traditional medicine to treat inflammatory conditions like rheumatoid arthritis and multiple sclerosis. BV is now widely used to treat a wide range of malignancies (6).

Apis mellifera is the most prevalent honey bee species in the Middle East. BV is a mixture of antibacterial, antioxidant and anti-cancerous active peptides, proteins, enzymes and other compounds (7).

Melittin is an essential component of BV. Melittin has a wide range of pharmacological and toxicological effects (8). Phospholipase A2 is also the most frequent enzyme in BV. It can split phospholipids in the sn2 membrane and release fatty acids such as arachidonic acid and lysophospholipids (9).

Cisplatin is used as a first-line treatment for a variety of cancers. It has been used to treat cancer of the head and neck, lung cancer, ovarian cancer, testicular cancer, as well as sarcomas (10).

Cisplatin's mechanism of action has been attributed to its capacity to crosslink with purine bases on DNA, interrupting DNA repair pathways, inducing DNA damage and eventually cancer cell death (11).

Due to cisplatin resistance and major side effects including nephrotoxicity, hepatotoxicity, gastrointestinal problems and bleeding, combination therapies combining cisplatin with natural products like BV have been used as unique therapeutic strategies for curing many human cancers (12).

P53 is regarded as the genome's guardian because it activates other genes that cause cell cycle arrest and DNA repair. P53 controls cisplatin-induced apoptosis via a variety of pathways including activation of pro-apoptotic genes and interactions with members of the $\mathrm{Bcl} 2$ family in the mitochondria and cytoplasm (13).

Caspase family proteases play a crucial part in the apoptosis mechanism. Caspase- 3 antibodies serve as excellent biomarkers for detecting induction of apoptosis. Caspases-3 activation is the first step in both intrinsic and extrinsic apoptotic pathways (14).

The purpose of this study was to see if BV and cisplatin had a synergistic cytotoxic effect on SCC- 25 cell line.

\section{Methods}

\section{Reagents}

The dried Apis mellifera venom was dissolved in normal saline $(0.9 \% \mathrm{NaCl})$.

Cisplatin with a chemical formula of PtCl2 (NH3)2 and a molecular mass of $300.05 \mathrm{~g} / \mathrm{mol}$. Cisplatin was dissolved in dimethyl sulphoxide (DMSO) (Sigma, USA) using an orbital shaker to yield a clear solution. 


\section{Cell Line}

SCC-25 cells were supplied from the cell culture department at VACSERA-EGYPT in the form of a frozen vial from the American Type Culture Collection with the reference number "CRL-1628.".

\section{Cell culture protocol}

In a $37^{\circ} \mathrm{C}$ humidified with $5 \% \mathrm{CO}_{2}$ incubator, SCC-25 cultures were grown in cultured flasks [GrinerGermany] in Dulbecco's modified Eagle's medium supplemented with $10 \%$ foetal bovine serum and $1 \%$ penicillin-streptomycin.

\section{Methyl Thiazol Tetrazolium assay protocol}

In 96 micro-titer plates $(5 \times 104$ cells $/ \mathrm{mL}), 1.2-1.8 \times 103$ SCC-25 cells were pre-cultured. The wells were filled with $10 \mathrm{~L}$ of MTT $\left(0.5 \mathrm{mg} / \mathrm{ml}\right.$ stock) solution and incubated at $37^{\circ} \mathrm{C}$ for 24 hours. The medium was removed, and the purple Formosan crystals were dissolved in 100L of DMSO.

The Dynatech MR5000 spectrophotometer (Dynatech Laboratories, Inc., Chantilly, VA) was used to measure the absorbance at $570 \mathrm{~nm}$, which was proportional to the number of live cells.

\section{Microscopic examination}

The Microscopic fields were photomicrographed at a magnification of 1000x oil immersion. The photomicrographs were assessed the existence of morphological apoptotic criteria.

\section{Evaluation of the expression of P53 and caspase-3 genes by RT-PCR}

The GeneJET RNA Purification kit [Fermantus-UK] was used to extract total RNA from control and treated SCC-25 cells according to the manufacturer's instructions. At a 260/280 nm ratio, the quantity and integrity of RNA were measured spectrophotometrically.

Quantitect Reverse Transcription kit [Qiagen, Germany] was used to synthesize first-strand cDNA using $1 \mathrm{~g}$ of total RNA, according to the manufacturer's instructions. The expression levels of the P53 and caspase3 genes were evaluated in these samples.

The endogenous expression standard was glyceraldehyde-3-phosphate dehydrogenase (GAPDH). On a Rotor-Gene Q cycler [Qiagen, Germany], quantitative RT-PCR was performed with QuantiTect SYBR Green PCR kits for forward and reverse primers for each gene.

The nucleic acid sequences of the primers were as follows:

P53 F 5'-ATGTGTGTGGAGACCGTCAA-3'.

P53 R 5'-GCCGTACAGTTCCACAAAGG-3'. 
Casp3 5'-TGTTTGTGTGCTTCTGAGCC-3'.

Casp3 5'-CACGCCATGTCATCATCAAC-3'.

GAPDH F 5'-AATGCATCCTGCACCACCAA-3'.

GAPDH R 5'-GATGCCATATTCATTGTCATA-3'.

\section{Statistical analysis}

Experimental finding were expressed as mean \pm standard deviation and analyzed using one-way analysis of variance (ANOVA) to determine the significance of differences between groups. $P<0.05$ was considered statistically significant.

\section{Results}

\section{MTT cytotoxicity assay}

In the current study, the possible cytotoxic influence of different concentrations of BV and cisplatin alone and BV/cisplatin mix was assessed 24 hours post treatment. Data obtained revealed that the cytotoxicity was dose dependent. The mean viability percentage of the treated cells decreased as the drug concentrations increased from $0.4 \mu \mathrm{g} / \mathrm{ml}$ to $100 \mu \mathrm{g} / \mathrm{ml}$. The $I_{50}$ values were $1.56 \mu \mathrm{g} / \mathrm{ml}, 12.56 \mu \mathrm{g} / \mathrm{ml}$ and $0.44 \mu \mathrm{g} / \mathrm{ml}$ for BV treated cells, cisplatin treated cells and BV/cisplatin mix treated cells respectively.

\section{Microscopic examination}

Our microscopic results showed that control SCC-25 cells were almost rounded with minimal folding in the cellular and nuclear membranes. SCC-25 showed criteria of malignancy such as hyperchromatism, nuclear pleomorphism and increased nuclear/cytoplasmic ratio.

On the other hand, SCC-25 treated cells exhibited morphological apoptotic characteristics. These criteria were obvious in BV and cisplatin treated cells, but they became more apparent in BV/cisplatin mix treated group. The apoptotic criteria included membrane blebbing, peripheral condensation of chromatin, nuclear shrinkage and nuclear fragmentation.

In addition to apoptotic criteria, some cells revealed nuclear alterations that resembled the morphological hallmarks of necrosis particularly with cisplatin treated SCC- 25 cells such as nuclear and cellular swelling, increased eosinophilia of the cytoplasm and cell membrane rupture.

In cisplain and BV/cisplatin mix treated SCC- 25 cells, the presence of secondary necrotic cells with both necrotic and apoptotic characteristics such as nuclear disintegration and cytoplasmic ballooning, as shown in figure 1.

Evaluation of the expression of P53 and caspase-3 genes by RT-PCR 
Regarding the apoptotic profiles of the tested drugs, RT-PCR analysis demonstrated that BV, cisplatin and $\mathrm{BV} /$ cisplatin mix significantly increased the expression levels of tumor suppressor protein gene P53 and caspases-3 when compared with control cells, as shown in figure 2.

\section{Statistical analysis}

ANOVA test demonstrated a high statistically significant difference between control and treated SCC-25 cells with various concentration of BV, cisplatin and BV/cisplatin mix for 24 hours $(P=0.0001)$.

\section{Discussion}

In both developing and developed countries, cancer is a leading cause of death. So, finding a more effective therapy strategy is crucial (15).

The most significant challenges of chemotherapy treatment are the development of drug resistance and undesired toxicity. The goal of cancer therapy is to maximize effect on cancer cells while minimizing influence on healthy cells (16).

The discovery of novel BV activities is a promising strategy for discovering natural treatments for cancer. Natural extracts of BV have been shown to have anticancer properties in numerous investigations (17).

Cisplatin is one of the most often used anticancer medications. Cisplatin kills cancer cells by disrupting nuclear and mitochondrial DNA, blocking DNA replication and triggering apoptosis. Cisplatin caused P53 activation, which resulted in cell death (18).

Combination therapy has been utilized to improve therapeutic response and reducing cisplatin resistance (19).

In this work, MTT assay was utilized to establish that BV and cisplatin successfully suppressed SCC-25 proliferation in a dosage manner, and that BV and cisplatin had a synergistic cytotoxic effect on SCC-25 cells. Our findings revealed a remarkable in-vitro cytotoxic effect of the tested drugs on SCC- 25 cells after 24 hours.

These findings were consistent with those of Gajski, Čimbora-Zovko et al. 2016, who found that BV and cisplatin had a cytotoxic influence and inhibited human glioblastoma A1235 cells in a dose-dependent manner (12).

Gajski, imbora-Zovko, et al. discovered that combining BV with cisplatin improved cytotoxicity, which could be beneficial for decreasing cisplatin concentration throughout treatment. Melittin produces hole in the cell membrane bilayer, which increases cisplatin uptake and accumulation, resulting in a synergistic increase in the cytotoxic effect of cisplatin (12).

$\mathrm{BV}$ and cisplatin in combination suppressed cell viability more effectively than BV and cisplatin alone as revealed in our findings. These findings supported the cytological analysis, which revealed that when 
drug concentrations increased, morphological apoptotic criteria increased as well.

SCC- 25 cells showed a considerable increase in apoptotic cells after 24 hours of BV/cisplatin mix therapy. There were also necrotic and secondary necrosis cells. Secondary necrosis is beneficial in cancer therapy because it indicates tumor cell death (20).

To confirm our results, P53 and caspase- 3 gene expression were evaluated using RT-PCR. P53 and caspase-3 genes were significantly up-regulated in SCC- 25 treated cells compared with control group. Furthermore, both drugs were found to be more effective when used together than when used separately.

This agreed with Jo, Kim et al. 2016 results who observed that after cisplatin therapy the expression levels of p53 and p21, as well as caspase-3, caspase-7 and caspase-9 were increased in oral squamous cell carcinoma cell line (21).

\section{Conclusions}

It can be concluded that, both BV and cisplatin induced a potent in-vitro cytotoxic effect in SCC- 25 cells via apoptosis. Using a mixed form exhibited a synergetic effect.

\section{Declarations}

\section{Ethics approval and consent to participate}

Not applicable: There are no human or animal experiments in this study, simply tongue squamous cell carcinoma cell line (SCC-25) obtained from American Type Culture Collection VACSERA-Egypt. No approvals were required for the study, which complied with all relevant regulations.

\section{Consent for publication}

Not applicable.

\section{Availability of data and material}

Not applicable.

\section{Competing interests}

The authors declare that they have no competing interests.

\section{Funding}

None. This research did not receive any specific grant from funding agencies in the public, commercial, or not-for-profit sectors.

\section{Authors' contributions}


SGK performed the morphological apoptosis investigations using the light microscope as well as was responsible for writing the background, methodology and submission process to JECl. MIS contributed in writing the results and discussion. SFE contributed to the design of the work and carried out the preparation of manuscript. AHE contributed to the revision of the whole work. All authors have read and approved the final manuscript.

\section{Acknowledgements}

Not applicable.

\section{Abbreviations}

Honey bee venom

BV.

Methyl Thiazol Tetrazolium

MTT.

Real time Polymerase chain reaction

RT-PCR.

Half-maximal inhibitory concentration

$\mathrm{IC}_{50}$.

World health organization

WHO.

Dimethyl sulphoxide

DMSO.

Glyceraldehyde-3-phosphate dehydrogenase

GAPDH.

One-way analysis of variance

ANOVA.

\section{References}

1. Sung H, Ferlay J, Siegel RL, Laversanne M, Soerjomataram I, Jemal A, et al. Global cancer statistics 2020: GLOBOCAN estimates of incidence and mortality worldwide for 36 cancers in 185 countries. CA: a cancer journal for clinicians. 2021;71(3):209-49.

2. Yosefof E, Hilly O, Stern S, Bachar G, Shpitzer T, Mizrachi A. Squamous cell carcinoma of the oral tongue: Distinct epidemiological profile disease. Head \& neck. 2020;42(9):2316-20.

3. Cramer JD, Burtness B, Le QT, Ferris RL. The changing therapeutic landscape of head and neck cancer. Nature reviews Clinical oncology. 2019;16(11):669-83.

4. Rayan A, Raiyn J, Falah M. Nature is the best source of anticancer drugs: Indexing natural products for their anticancer bioactivity. PloS one. 2017;12(11):e0187925. 
5. Wehbe R, Frangieh J, Rima M, El Obeid D, Sabatier J-M, Fajloun Z. Bee venom: Overview of main compounds and bioactivities for therapeutic interests. Molecules. 2019;24(16):2997.

6. Kim KH, Kim M, Lee J, Jeon HN, Kim SH, Bae H. Comparison of the protective effects of bee venom extracts with varying pla2 compositions in a mouse model of parkinson's disease. Toxins. 2019;11(6):358.

7. Frangieh J, Salma Y, Haddad K, Mattei C, Legros C, Fajloun Z, et al. First characterization of the venom from Apis mellifera syriaca, a honeybee from the Middle East region. Toxins. 2019;11(4):191.

8. El Bakary NM, Alsharkawy AZ, Shouaib ZA, Barakat EM. Role of bee venom and melittin on restraining angiogenesis and metastasis in $\mathrm{Y}$-irradiated solid ehrlich carcinoma-bearing mice. Integrative Cancer Therapies. 2020;19:1534735420944476.

9. Yaacoub C, Rifi M, El-Obeid D, Mawlawi H, Sabatier J-M, Coutard B, et al. The Cytotoxic Effect of Apis mellifera Venom with a Synergistic Potential of Its Two Main Components-Melittin and PLA2-On Colon Cancer HCT116 Cell Lines. Molecules. 2021;26(8):2264.

10. Qi L, Luo Q, Zhang Y, Jia F, Zhao Y, Wang F. Advances in toxicological research of the anticancer drug cisplatin. Chemical research in toxicology. 2019;32(8):1469-86.

11. Kleih M, Böpple K, Dong M, Gaißler A, Heine S, Olayioye MA, et al. Direct impact of cisplatin on mitochondria induces ROS production that dictates cell fate of ovarian cancer cells. Cell death \& disease. 2019;10(11):1-12.

12. Gajski G, Čimbora-Zovko T, Rak S, Osmak M, Garaj-Vrhovac V. Antitumour action on human glioblastoma A1235 cells through cooperation of bee venom and cisplatin. Cytotechnology. 2016;68(4):1197-205.

13. Ciccarone F, De Falco P, Ciriolo MR. Aconitase 2 sensitizes MCF-7 cells to cisplatin eliciting p53mediated apoptosis in a ROS-dependent manner. Biochemical Pharmacology. 2020;180:114202.

14. Yadav P, Yadav R, Jain S, Vaidya A. Caspase-3, a primary target for natural and synthetic compounds for cancer therapy. Chemical Biology \& Drug Design. 2021.

15. Torre LA, Bray F, Siegel RL, Ferlay J, Lortet-Tieulent J, Jemal A. Global cancer statistics, 2012. CA: a cancer journal for clinicians. 2015;65(2):87-108.

16. Wang X, Zhang H, Chen X. Drug resistance and combating drug resistance in cancer. Cancer Drug Resistance. 2019;2(2):141-60.

17. Carpena M, Nuñez-Estevez B, Soria-Lopez A, Simal-Gandara J. Bee Venom: An Updating Review of Its Bioactive Molecules and Its Health Applications. Nutrients. 2020;12(11):3360.

18. Zhu H, Luo H, Zhang W, Shen Z, Hu X, Zhu X. Molecular mechanisms of cisplatin resistance in cervical cancer. Drug design, development and therapy. 2016;10:1885.

19. Alonezi S, Tusiimire J, Wallace J, Dufton MJ, Parkinson JA, Young LC, et al. Metabolomic profiling of the synergistic effects of melittin in combination with cisplatin on ovarian cancer cells. Metabolites. 2017;7(2):14.

20. Galluzzi L, Kroemer G. Secondary necrosis: accidental no more. Trends in cancer. 2017;3(1):1-2. 
21. Jo D-W, Kim Y-K, Yun P-Y. The influence of p53 mutation status on the anti-cancer effect of cisplatin in oral squamous cell carcinoma cell lines. Journal of the Korean Association of Oral and Maxillofacial Surgeons. 2016;42(6):337-44.

\section{Figures}

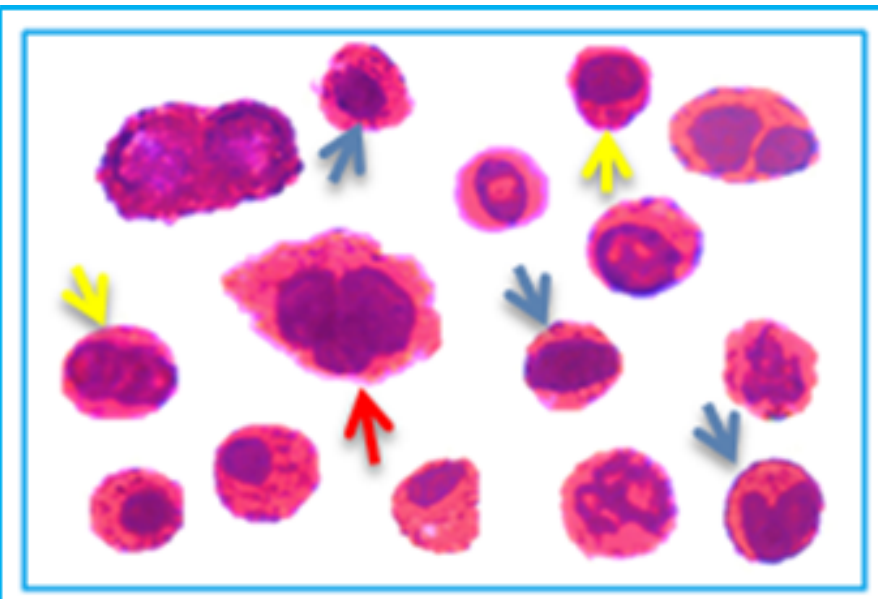

(a)

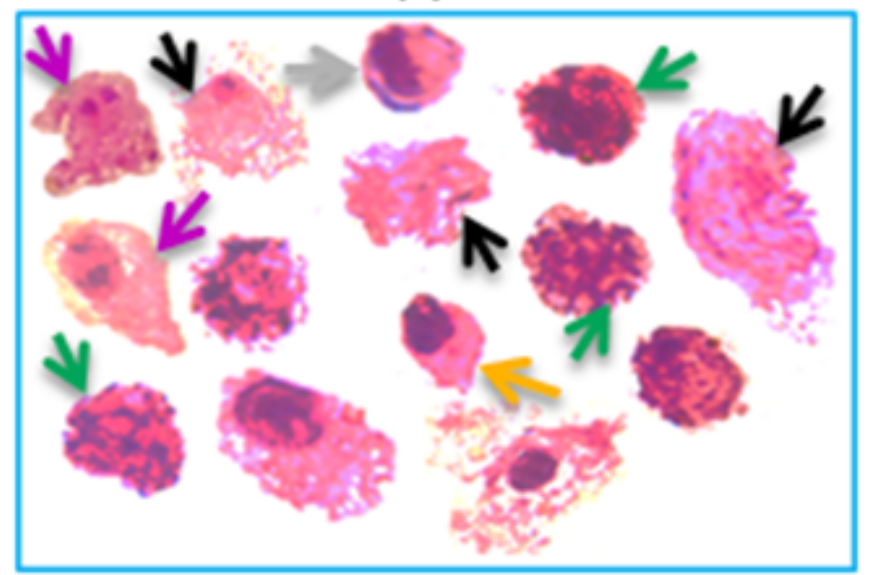

(c)

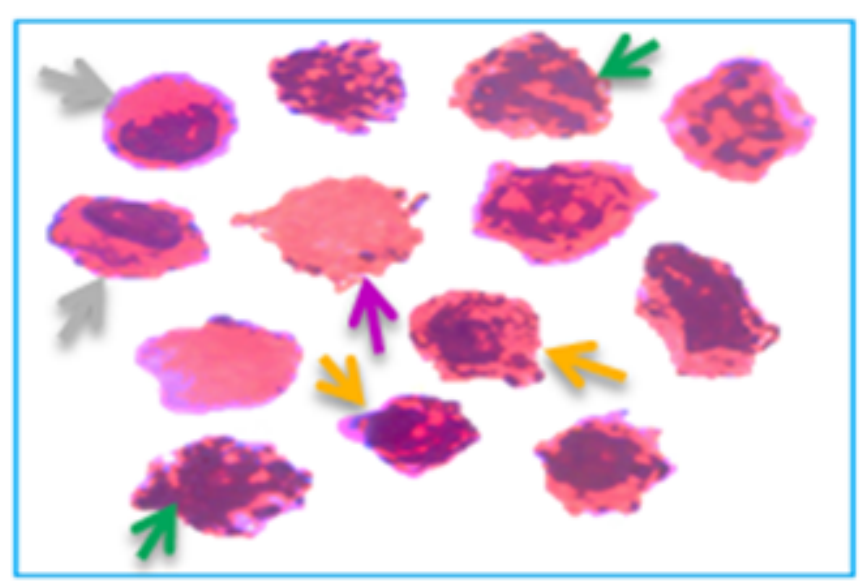

(b)

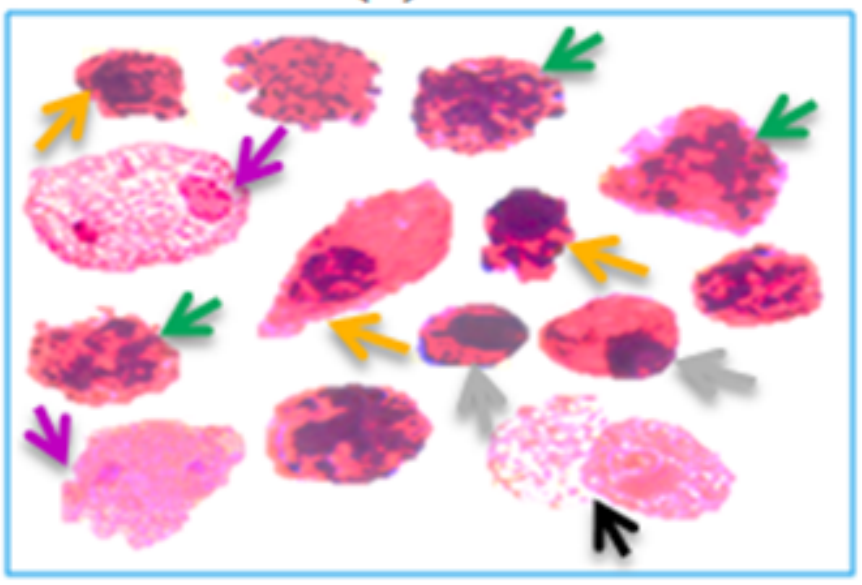

(d)

\section{Figure 1}

Photomicrographs of (a) control cells, (b) BV treated cells, (c) cisplatin treated cells and (d) BV/cisplatin mix treated cells showing: hyper chromatic nuclei (blue arrows), abnormal mitotic figure (red arrow), increased nuclear cytoplasmic ratio (yellow arrows), membrane blebbing (orange arrows), peripheral chromatin condensation (grey arrows), necrotic cells (black arrows), nuclear fragmentation (green arrows) and secondary necrotic cells (purple arrows) (H \& E x 1000 oil). 


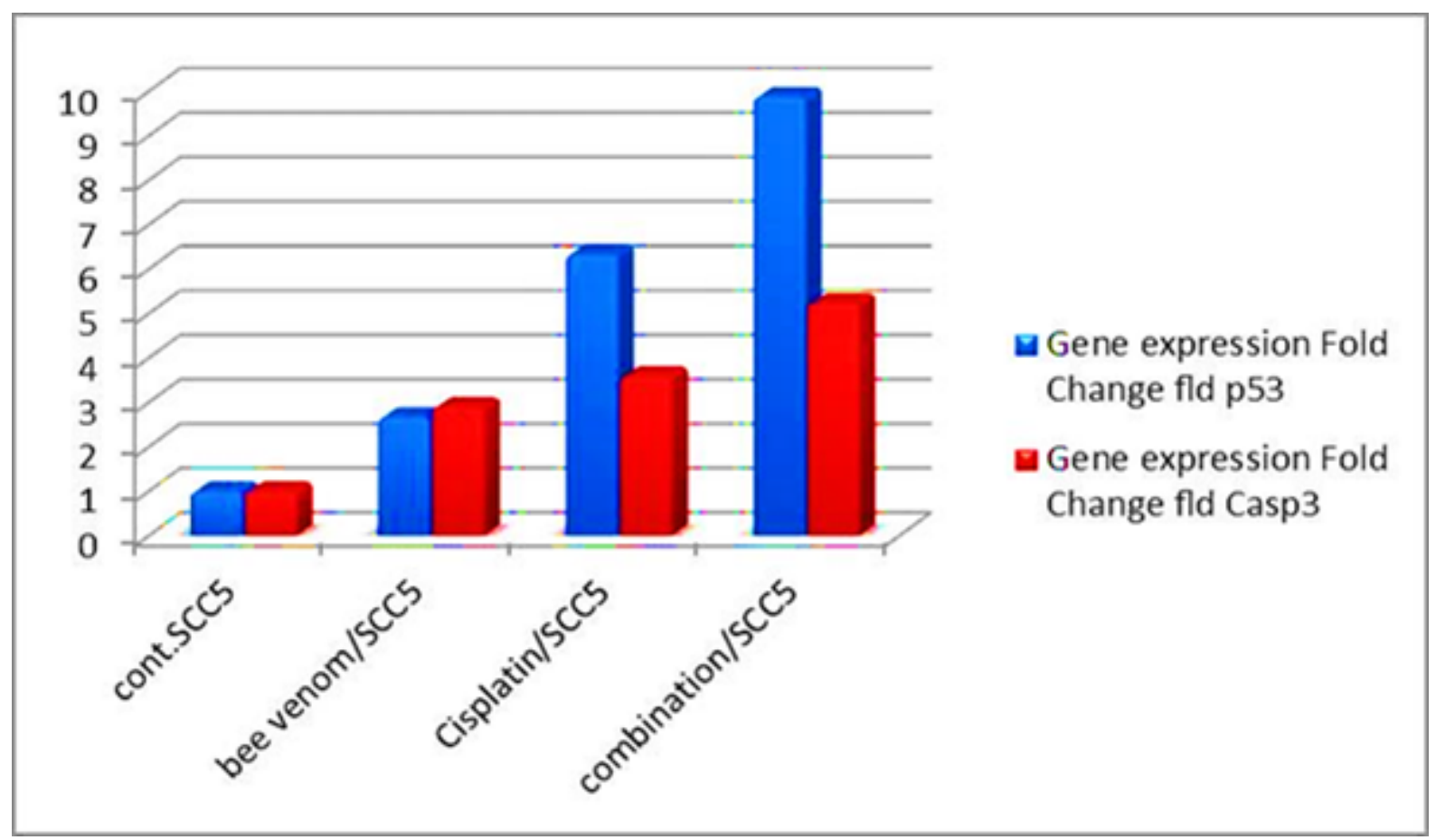

Figure 2

P53 and Caspase-3 genes fold changes using RT-PCR in control and SCC- 25 treated cells with BV, cisplatin and BV/cisplatin mix for 24 hours. 